\title{
Análise temporal da ocupação dos vazios urbanos no período entre revisões do plano diretor - estudo de caso da cidade de São Carlos - SP.
}

\author{
Temporal analysis of the occupation of urban voids in the period in revisions of the \\ master plan- case study of the city of São Carlos - SP.
}

Análisis temporal de la ocupación de los vacíos urbanos en el período entre revisiones del plan director- estudio de caso de la ciudad de São Carlos - SP.

\author{
Yanayne Benetti Barbosa \\ Doutora, UFSCAR, Brasil. \\ yanayne@gmail.com.br \\ Luciana Márcia Gonçalves \\ Professora Doutora, UFSCAR, Brasil. \\ lucianamg@ufscar.br \\ José Augusto de Lollo \\ Professor Doutor,UNESP, Brasil. \\ ja_lollo@yahoo.com
}




\section{RESUMO:}

Este trabalho apresenta o mapeamento e a análise temporal da ocupação dos vazios urbanos no período entre revisões do Plano Diretor de Desenvolvimento Urbano. São analisados os vazios urbanos nos anos de 2004 e 2014, anos de realização de levantamento de dados e diagnósticos espaciais na cidade de São Carlos, SP. Como resultado, ressalta-se que a ocupação prevista no zoneamento e estratégias de ocupação no Plano Diretor de 2005, não ocorreu completamente conforme previsto. Com a detalhada localização dos vazios existentes e os que ainda permaneceram 10 anos depois foi possível identificar a ocupação urbana e inclusive os avanços do perímetro urbano frente a ação dos agentes produtores do espaço da cidade. Para a produção do material cartográfico foram utilizadas ferramentas de Geoprocessamento e Sistemas de Informação Geográfica.

PALAVRAS-CHAVE: Planejamento Urbano. Vazio Urbano. Plano Diretor.

\section{ABSTRACT:}

This paper presents the mapping and temporal analysis of the occupation of urban voids in the period between revisions of the Urban Development Master Plan. Urban voids are analyzed in the years 2004 and 2014, years of data collection and spatial diagnostics in the city of São Carlos, SP. As a result, it is emphasized that the occupation foreseen in the zoning and occupation strategies in the 2005 Master Plan did not occur completely as planned. With the detailed location of the existing voids and those that remained 10 years later it was possible to identify the urban occupation and even the advances of the urban perimeter with the action of the producing agents of the city space. Geoprocessing tools and Geographic Information Systems were used for the production of cartographic material.

KEY WORDS: Urban Planning. Urban Void. Master Plan.

\section{RESUMEN:}

Este trabajo presenta el mapeamiento y el análisis temporal de la ocupación de los vacíos urbanos en el período entre revisiones del Plan Director de Desarrollo Urbano.Se analizan los vacíos urbanos en los años 2004 y 2014, años de realización de levantamiento de datos y diagnósticos espaciales en la ciudad de São Carlos, SP. Como resultado, se resalta que la ocupación prevista en la zonificación y estrategias de ocupación en el Plan Director de 2005, no ocurrió completamente según lo previsto.Con la detallada localización de los vacíos existentes y los que aún permanecieron 10 años después fue posible identificar la ocupación urbana, incluso los avances del perímetro urbano frente a la acción de los agentes productores del espacio de la ciudad. Para la producción del material cartográfico se utilizaron herramientas de Geoprocesamiento y Sistemas de Información Geográfica.

PALABRAS CLAVE: Planificación Urbana. Vacío Urbano. SIG. Plan Maestro. 


\section{INTRODUÇÃO}

No Brasil, se considerarmos a história das cidades, podemos verificar que o processo de ocupação do território urbano foi definitivo na primeira metade do século XX e irreversível a partir da 2a metade do século XX. As cidades são produzidas, conforme Corrêa (2003) pelos agentes produtores do espaço, que são os proprietários dos meios de produção, os proprietários fundiários, os proprietários imobiliários, o Estado e os grupos sociais excluídos. Esses agentes agem de diferentes formas e, em determinadas situações, possuem mais de um papel, porém cada agente possui objetivos distintos e que também podem ser conflitantes no aspecto territorial, principalmente. Ao analisar o meio urbano e o cotidiano, Lefebvre (1991) destaca que esses agentes são produtos e produtores do espaço urbanizado.

A fim de orientar o crescimento, a gestão e o desenvolvimento das cidades brasileiras, o Estatuto da Cidade (LEI FEDERAL 10.257, Brasil 2001) previu alguns instrumentos, dentre eles o Plano Diretor Municipal. Por pressuposto, o Plano Diretor deve direcionar quais tipos de vazios urbanos devem ser ocupados, tendo em vista que são áreas não edificadas, localizadas em meio à malha urbana (com disponibilidade de infraestrutura), mas que estão subutilizadas ou desocupadas.

\section{OBJETIVOS}

Como objetivo geral, busca-se analisar a ocupação dos vazios da cidade de São Carlos em dois marcos temporais 2004 e 2014, período esse que coincide com os diagnósticos de revisão dos últimos Planos Diretores aprovados, portanto espera-se obter, através da localização desses vazios, o perfil da ocupação e analisar a influência do Plano Diretor de 2005.

\section{METODOLOGIA}

Definiu-se para uso neste estudo o sistema de projeção a ser trabalhado: Projeção Geográfica Universal Transversa de Mercator (UTM), Datum Horizontal WGS 84, Fuso 23 Sul para cidade de São Carlos-SP. Os dados foram inseridos, dentro do diretório um Bancos de Dados Geográficos utilizando um Esri Personal Geodatabase (GDB) no software ARCGis. Foi realizado a identificação e vetorização do contorno dos vazios urbanos lotes e glebas junto a imagem de Satélite GeoEye de 2014 e o limite urbano de 2016 e utilizando a imagem de IKONOS de 2004 e o limite urbano de 2005.

plicou-se a sobreposição no ArcGis com o chamado intersect de cada zona urbana(zoneamento ambiental) individualizada com o layer de vazios urbanos (lote) de $2004 \mathrm{e}$ 2014. Depois a mesma zona urbana foi feita a sobreposição com o layer vazios urbanos (glebas) de 2004 e 2014. E o mesmo processo se repetiu para todas as zonas urbanas dos anos de 2005 e 2016. 


\section{Revista Nacional de}

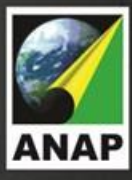

Gerenciamento de Cidades

National Journal of Cities Management

\section{RESULTADOS}

Neste trabalho, considera-se a definição de "vazio urbano" como toda área já parcelada ou ainda não parcelada, localizada em meio à malha urbana consolidada, sendo subutilizada ou desocupada. Dentro deste contexto, foi realizada a identificação dos vazios urbanos em dois períodos definidores de politicas públicas urbanas para a cidade de São Carlos, nos anos de 2004 e 2014.

Os vazios urbanos de 2004 Figura 1, foram identificados na época da elaboração do Plano Diretor o qual foi aprovado e implantado em 2005. O Plano Diretor estabelece o cumprimento da função social de cidade conforme suas diretrizes (LEI MUNICIPAL no 13.691/05- PDSC 2005). Nesse sentido no Plano Diretor de 2005, o município foi dividido por zoneamentos rural e urbano. As zonas urbanas foram divididas em quatro tipos: a zona marcada por (1) corresponde à ocupação induzida; (2) corresponde à ocupação condicionada; (3) corresponde à recuperação e ocupação controlada e (5) corresponde à proteção e ocupação restrita, a qual está parcialmente inserida no perímetro urbano.

Sobre as zonas urbanas, Bizzio (2015, p.66) ressalta que a zona 1 e zona 2 buscam oferecer melhores índices de aproveitamento e ocupação do solo, além de menores restrições construtivas, buscando adensar a região central da cidade (a exceção se deu com a zona 3, localizada na região sul e leste, composta por solo arenoso (3A) e ocupada pela população de menor renda, e pelos principais mananciais de abastecimento da cidade (3B)). Concomitante ao adensamento da região central, o plano demarcou as áreas passíveis de expansão urbana, localizadas a norte e oeste. Essa área está situada na zona 4 (4A e 4B), e visando frear a construção de parcelamentos dispersos e estimular o adensamento, recai sobre ela uma outorga onerosa de alteração do uso do solo, estipulada em $5 \%$ do valor do terreno. (BIZZIO, 2015, p.66). 


\section{Revista Nacional de}

Gerenciamento de Cidades

Figura 1- Vazios Urbanos diagnosticados no ano de 2004

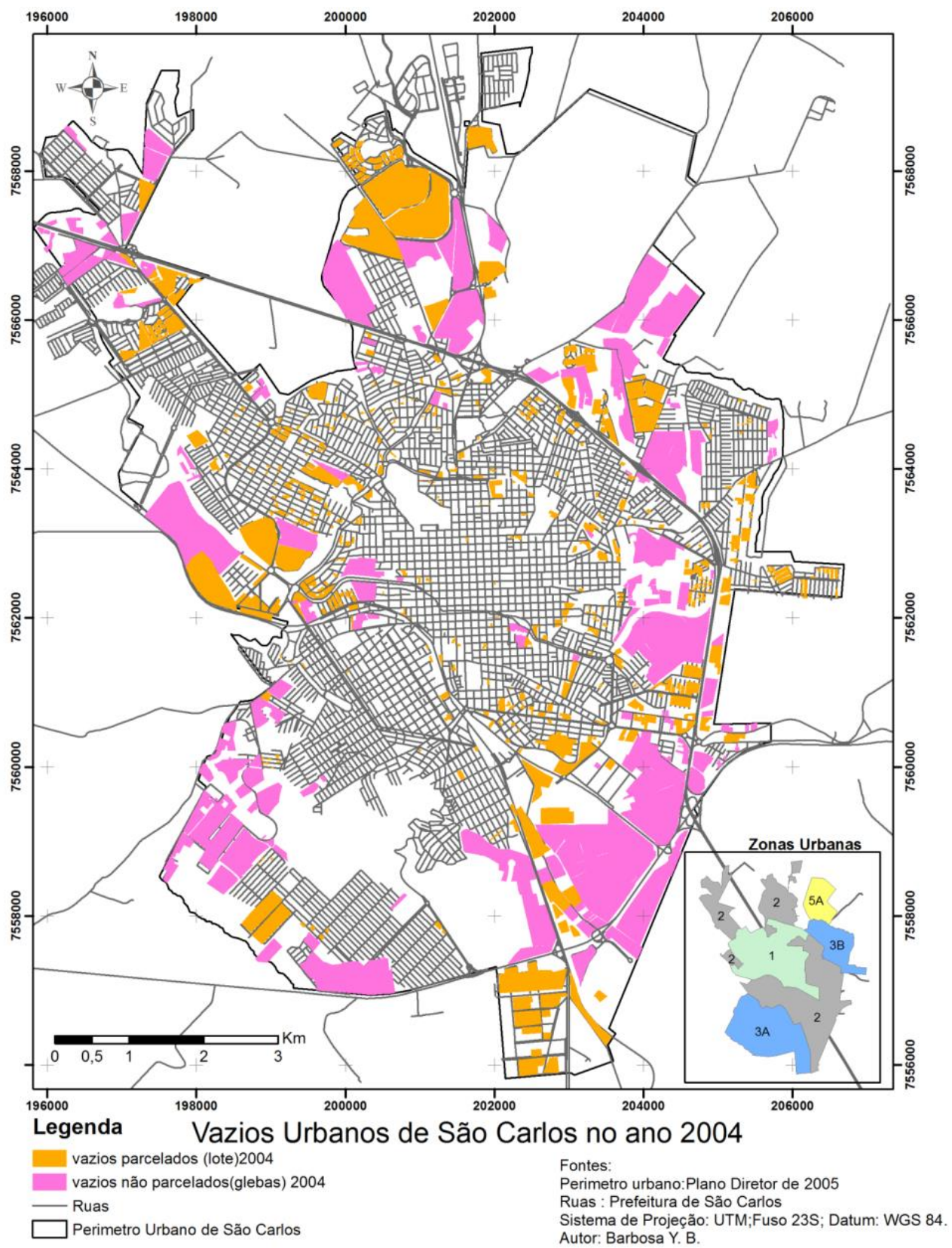

Fonte: adaptado por Barbosa, Y. B. (2018)

Destaca-se o espraiamento dos vazios urbanos no ano de 2004 na Figura 1 e ao mesmo tempo uma maior concentração de vazios na zona (2) e zona (3) na área urbana de São Carlos. 
O Plano Diretor de 2005 previu o processo de revisão a cada dez anos. Dessa forma, foi realizada a segunda e última revisão em 2016 (LEI MUNICIPAL no 18.053 de 19 de Dezembro de 2016-PDSC, 2016), que possui como característica a maior segmentação do zoneamento de uso e ocupação do solo urbano e alteração do perímetro urbano.

Para o estudo do Plano Diretor de 2016 foi utilizada a localização dos vazios urbanos do ano de 2014, ver Figura 2.

Destaca-se no Plano Diretor de 2016, cinco tipos de zonas urbanas: Zona de Ocupação Consolidada (1), Zona de Ocupação Induzida (2), Zona de Ocupação Condicionada (3), Zona de Qualificação e Ocupação Controlada (4), Zonas 5A e 5B - Proteção e Ocupação Controlada.

A região central, onde se localiza a Zona 1 - Zona de Ocupação Consolidada é provida de todos os tipos de infraestrutura, além de imóveis de interesse histórico e edificações. Sua primeira diretriz é promover a ocupação dos imóveis vazios ou subutilizados.

A região da Zona 2 - Zona de Ocupação Induzida está na porção superior da área urbana atravessando a mancha urbana no sentido noroeste e leste. Ela está totalmente inserida entre a Rodovia Washington Luiz e a Ferrovia e pode ser melhor compreendida pela descrição no art. 20 do PDSC, 2016 no seu parágrafo único, no qual caracteriza tal zona por sua disponibilidade de infraestrutura instalada, destacando o sistema viário fragmentado e deficitário apresentado em outras zonas. Destaca a presença de muitos vazios urbanos com localização dispersa na zona e totalmente passíveis de parcelamento e ou edificação.

A Zona 3 - Zona de Ocupação Condicionada é segmentada e abrangem as regiões norte, nordeste, sudeste. As regiões nordeste e norte apresentam muitos lotes vazios concentrados em áreas de condomínios fechados. O numero de áreas (glebas ou lotes) vazios reduziram em relação ao período anterior, porém num movimento cíclico, verificou-se que, com o tempo, algumas glebas foram parceladas, lotes foram ocupados e grandes glebas foram fragmentadas em áreas menores. A alteração do limite do perímetro urbano, a mudança de uso do solo e a incorporação de novas áreas fez com que surgissem mais espaços vazios dentro da área urbana.

A Zona 4 - Zona de Qualificação e Ocupação Controlada está localizada na região Sul. Está inserida toda a bacia do córrego da Água Quente. Destaque que conforme o próprio plano diretor de São Carlos considera a bacia do córrego da Água Quente como uma das regiões que mais sofrem com problemas de erosão. A extensa bacia de contribuição aliada a insuficiente rede de drenagem torna o local palco de inúmeros problemas erosivos, PDDUASSC, 2009 p.62. Na região Sul está localizado os novos loteamentos populares, dentre os quais, o programa Minha Casa Minha Vida (MCMV), serve de exemplo, pois promoveram habitação de interesse social em quantidade significativa para a cidade de São Carlos, nas faixas 1 e 2. Pode-se mencionar o levantamento de Lopes, Shimbo (2015) que localizou os empreendimentos no período entre 2009, quando foi lançado o Programa, e o final de 2012 de São Carlos. Esses loteamentos caracterizam-se por estarem na faixa 1 do MCMV (residencial Jardim Gramado, conjunto habitacional Planalto Verde e o residencial Eduardo Abdelnur), todos construídos, forçando a expansão da fronteira urbana. 


\section{Revista Nacional de}

As Zonas 5A e 5B - Proteção e Ocupação Controlada corresponde às regiões de proteção dos mananciais do Monjolinho-Espraiado e do Ribeirão do Feijão. Estão localizadas a nordeste e sudeste na malha urbana. Tem grandes quantidades de glebas de áreas maiores que 10.000 $\mathrm{m}^{2}$. Para a Zona $5 \mathrm{~A}$, em virtude de suas fragilidades, geográficas e morfológicas, faz-se necessário pensar em implantar técnicas compensatórias nas glebas vazias além do uso residencial e comercial incluindo habitação social de baixa densidade. Para Zona 5B, por estar em área de parque industrial faz-se necessário também seguir a diretrizes e aplicar os estudos de Impacto de vizinhança (EVI). 
Revista Nacional de

Gerenciamento de Cidades

National Journal of Cities Management

Figura 2- Vazios Urbanos parcelados e não parcelados no ano de 2014

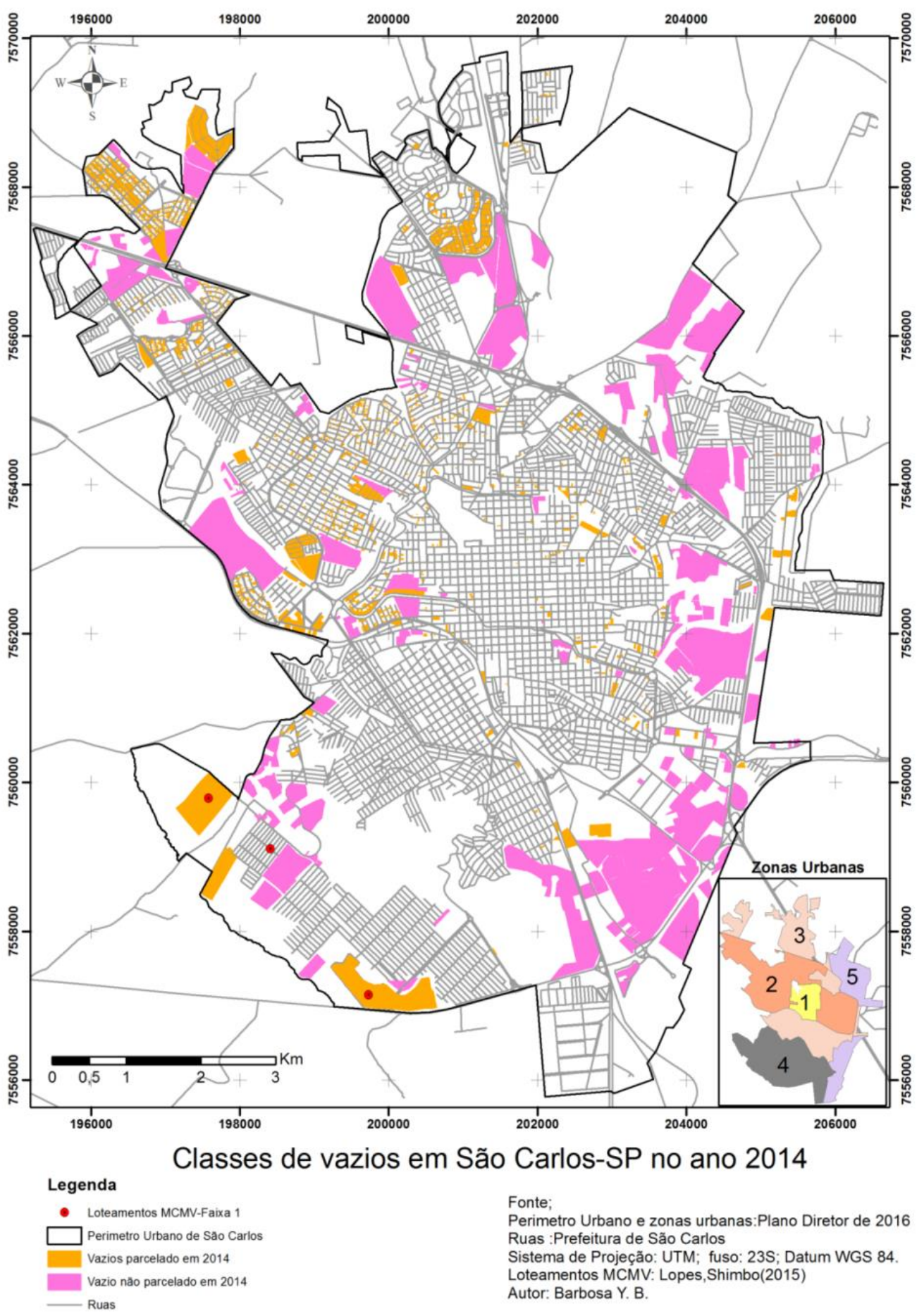

Fonte: Barbosa Y B (2018)

De posse dos vazios urbanos em base georreferenciada, foi possível analisar a dinâmica de sua formação e de sua ocupação por meio de SIG, para os períodos de 2004 e 2014. Percebeu-se 
uma mudança na categoria (gleba e lote) no mapa de vazio urbano do ano 2004 para 2014. Os vazios urbanos que no ano de 2004 eram considerados glebas, passaram por um processo de loteamento no decorrer do tempo e transformaram-se na categoria de vazios parcelados (lotes). Essa é uma consequência da mudança na dinâmica da cidade, verificada no Plano Diretor de 2005, que motivou o parcelamento desses vazios, sem garantir, porém, a ocupação dos mesmos.

A ferramenta de SIG, utilizada para localizar quais vazios urbanos foram ocupados no decorrer dos anos, foi a álgebra de mapas, junto da ferramenta eraser no SIG ArcGis. Para obter o mapa da Figura 3, foi aplicado o cruzamento dos vazios urbanos de 2004 com os vazios urbanos de 2014, resultando no layer das áreas ocupadas.

A compreensão do padrão da ocupação ou da permanência dos vazios urbanos é estruturante neste trabalho. Nesse sentido, observam-se, na Figura 3 os polígonos de onde foram ocupadas as glebas e os lotes na área urbana de São Carlos. É perceptível que a ocupação foi mais pulverizada na malha urbana, ou seja, não houve concentração de ocupação.

Pode-se fazer uma análise entre as zonas da cidade. A zona norte tem empreendimentos de alto valor imobiliário, é onde se situam os imóveis de maiores valores e população de maior renda e teve um avanço na ocupação por meio de loteamentos fechados em áreas fora do perímetro urbano, trazendo mudanças de uso e ocupação da terra.

Na região central, onde havia poucos lotes e glebas vazias, a mudança de padrão e ocupação foi menos significativa no decorrer dos anos, exceto para uma análise de adensamento, o que não foi alvo deste trabalho. Identificou-se um aumento da verticalização nas áreas próximas ao centro e à universidade USP, em que foram identificadas demolições de casas para construção de prédios, adensando áreas já ocupadas em detrimento de ocupar vazios em outras regiões, o que demonstra o interesse nos imóveis de alta valorização locacional. Os valores venais destas glebas estão entre os mais altos na planta genérica de valores de 2017, mesmo assim, a inciativa privada não conseguiu dar finalidade social e ou econômica para as duas glebas.

Na região sul, houve ocupação de áreas não previstas no Plano Diretor, especialmente para habitação de interesse social (HIS). O programa Minha Casa Minha Vida (MCMV), promoveu HIS em quantidade significativa na cidade de São Carlos, na faixa 1 e 2. Deve-se ressaltar o levantamento de Lopes e Shimbo (2015), que localizou os empreendimentos no período entre 2009, quando foi lançado o Programa, e ao final de 2012. Os loteamentos enquadrados na faixa 1 do MCMV (residencial Jardim Gramado, conjunto habitacional Planalto Verde e o residencial Eduardo Abdelnur) foram construídos forçando a expansão da fronteira urbana. Esse tipo de empreendimento aumenta a concentração da população de baixa renda em locais distantes de equipamentos públicos, carentes de infraestrutura de transporte público.

Contraditoriamente a essa política de ocupação de vazios do Plano Diretor de 2005, foram encontrados novos loteamentos que demandaram expansão do perímetro urbano. Portanto, apesar do Plano Diretor de 2005 definir estratégia de ocupação dentro do limite do perímetro urbano, novos loteamentos foram implantados na cidade, visando principalmente a habitação 


\section{Revista Nacional de}

de interesse social e condomínios horizontais, desconsiderando o zoneamento e a direção do vetor de expansão da cidade.

Foi constatada, por meio da álgebra de mapas, uma redução de vazios urbanos em São Carlos em 2014 em relação aos vazios de 2004. Tal redução pode ser atribuída não só à política urbana prevista no Plano Diretor de 2005, mas também à dinâmica econômica do período. 0 mercado imobiliário teve forte atuação com muitos novos empreendimentos aprovados. Neste estudo, obteve-se a localização das áreas ocupadas, com destaque para os grandes empreendimentos residenciais, entre eles condomínios horizontais para alta renda e conjunto residências de Habitação de Interesse Social (HIS). 
Revista Nacional de

Gerenciamento de Cidades National Journal of Cities Management

Figura 3-Glebas e lotes urbanos ocupados no período de 2004-2014.

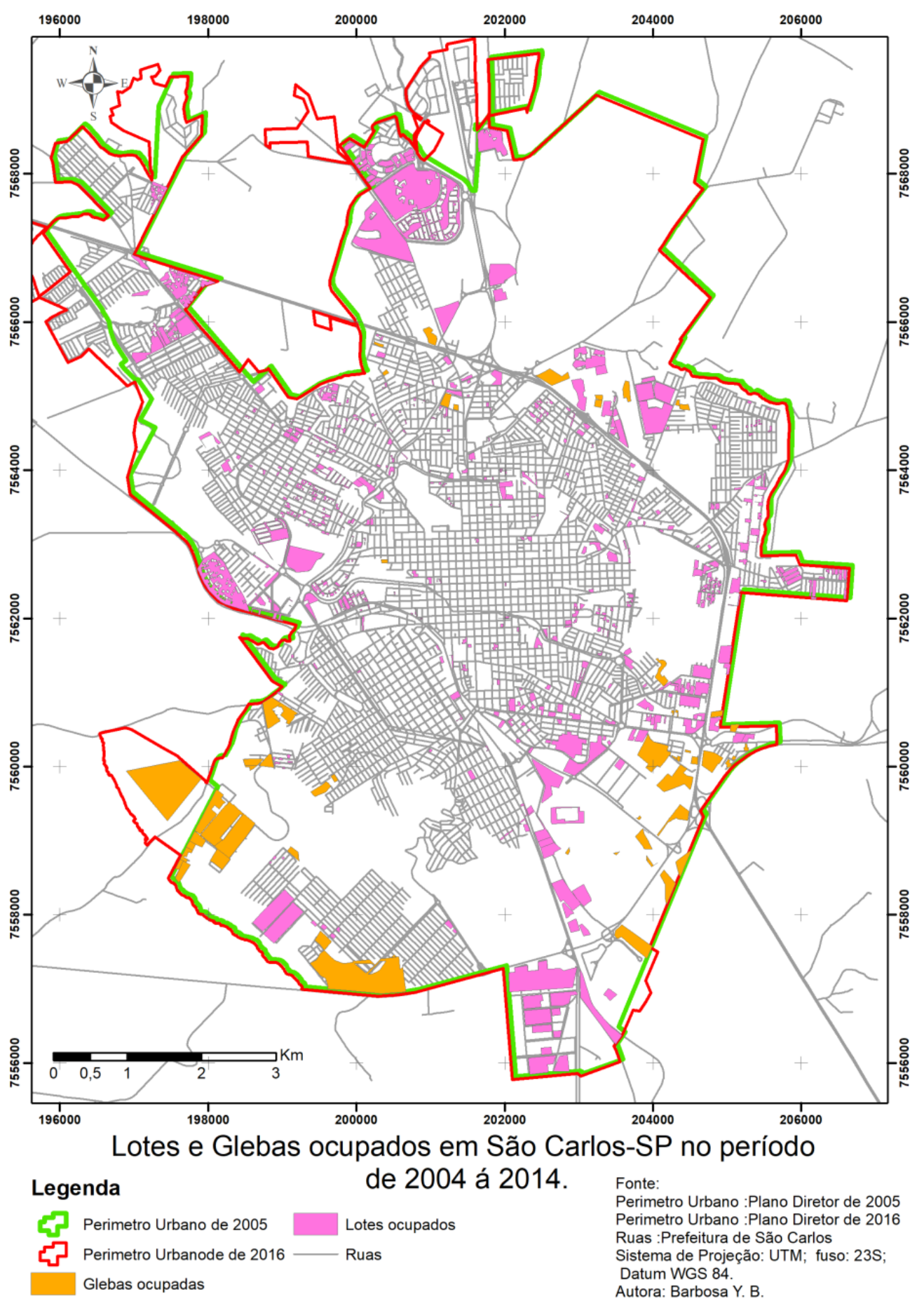

Fonte: Barbosa Y B (2018) 


\section{CONCLUSÃO}

Como marco temporal, aproveitou-se a oportunidade de dados gerados pelas revisões dos dois últimos Planos Diretores da cidade de São Carlos, aprovados em 2005 e 2016, gerando importante documentação histórica e físico-territorial da cidade.

Destaca-se que a área de vazios urbanos de São Carlos, à época do diagnóstico e aprovação do Plano Diretor de 2005, era 23 \% da área total urbana. Porém, no ano de 2014, as dinâmicas dos vazios urbanos foram diferentes, os vazios têm um valor de $15 \%$ da área total. Houve uma redução na quantidade de vazios no decorrer do tempo e essa variação foi mais significativa na classe de lotes e/ou glebas. Entendemos que o mercado imobiliário foi muito atuante na implantação de loteamentos dentro e fora do perímetro urbano e o poder público municipal oscilou entre regulador e empreendedor que age a favor do capital imobiliário, em detrimento de uma visão mais abrangente da cidade, como, por exemplo, aprovando loteamentos em áreas quase sem infraestrutura, muito distante do centro comercial e até mesmo fora do perímetro urbano.

Dentre as conclusões, evidencia-se o uso não adequado do instrumento urbanístico incorporado ao Plano Diretor de São Carlos em 2005, a Outorga Onerosa de Alteração do Uso acabou por propiciar ambiente favorável ao mercado imobiliário. Além disso, a falta de aplicação do IPTU progressivo fez com que os vazios continuassem sem ocupação nas áreas centrais urbanas.

Novas construções e parcelamentos demandam de todo tipo de infraestrutura e, no caso de loteamentos distantes e condomínios fechados, aumentam a segregação sócio- espacial através do uso habitacional em São Carlos. Destaca-se a importância de analisar no território da cidade a ocupação e o impacto, atual e futuro, e não só nas repercussões imediatista de uma demanda habitacional. Uma vez que estes resultaram em loteamentos mal planejados quanto a localização e aproveitamento da infraestrutura disponível na cidade. Conforme os levantamentos realizados, existem muitas áreas para serem ocupadas dentro do perímetro urbano, portanto, cabe ao poder público local direcionar a ocupação para tais áreas visando a uma cidade compacta e servida de infraestrutura para todos.

Observou-se que mesmo com a aprovação os Planos Diretores de 2005 e 2016, o setor imobiliário conduz os investimentos e faz definir as regras de ocupação do território urbano. É função do poder público municipal principalmente, por meio dos instrumentos urbanísticos regulamentados pelo Estatuto da Cidade e aplicados pelos Planos Diretores, combater tal pressão, evitando a segregação sócio espacial e os altos investimentos públicos em infraestrutura e equipamentos sociais dispersos na cidade.

A ocupação prevista para os investimentos habitacionais de interesse social no Plano Diretor de 2005, não ocorreu conforme previsto nas áreas de especial ocupação para habitação social (AEIS). Este estudo identificou as áreas de lotes e áreas de glebas livres para a habitação em 2004 e identificou que após a implantação do Plano Diretor de 2005, as AEIS destinadas ao interesse social não foram ocupadas pelos novos loteamentos populares, estes foram 
implantados em terras longínquas em que o valor da terra era mais baixo, porém os investimentos em infraestrutura a serem realizados a posteriori pela Prefeitura, principalmente, não foram computados.

Dez anos depois, ou seja, em análise dos dados em 2014, pôde-se verificar que houve ocupação em alguns vazios com densidade baixa na vizinhança, mas também houve a implantação de loteamentos sociais e loteamentos de condomínios fechados fora do perímetro urbano. Na revisão do Plano Diretor ocorrida em 2016, foi ampliado o limite urbano para incluir estas áreas. Isso demostra claramente a predominância do mercado imobiliário com anuência do Poder Público Municipal em muitos momentos e que, por fim, determinaram a forma do crescimento da cidade, sem priorizar e atender às premissas do Plano Diretor conforme aprovação e debate público que originou tais proposições.

Segundo estudos já realizados no âmbito desse grupo de pesquisa, Barbosa (2018), é possível afirmar que em $73 \%$ dos casos na área urbana, a regra é que a valorização da gleba ocorre por conta da localização e da quantidade de instrumentos disponibilizados a áreas sem ocupação (vazios urbanos). Salvo a exceção de locais próximos ao vetor de expansão da cidade e de interesse político ou até especulativo, que não foram objeto de detalhamento desse estudo.

Espera-se que o novo Plano Diretor de 2016, por meio da prática dos gestores, não priorize a expansão territorial urbana e a gestão proporcione incentivos à ocupação de áreas adequadas e a diversificação do uso do solo, além de ter um planejamento de transportes e mobilidade integrados ao planejamento do uso do solo com desenvolvimento da promoção social, ambiental e econômica.

Os resultados apresentados reforçam a necessidade de que os agentes públicos apliquem as políticas urbanas que foram planejadas, e coloquem em prática as medidas de combate à permanência de vazios que impactam no custo da urbanização para se ter um melhor aproveitamento da infraestrutura existente e dos serviços prestados às áreas de vazios urbanos. A busca de territórios e de espaços disponíveis e infraestrutura da localização privilegiada dos vazios urbanos representam uma oportunidade de planejamento sócio espacial, tendo em vista que sua ocupação pode promover e cumprir a função social da propriedade e do solo urbano.

\section{REFERÊNCIAS BIBLIOGRÁFICAS}

BARBOSA Y. B. Análise temporal do processo de ocupação dos vazios urbanos no município de São Carlos, sp: sob a ótica de uma cidade compacta. Tese de Doutorado. Programa de Pós-Graduação em Engenharia Urbana da Universidade Federal de São Carlos. 186p. 2018.

BIZZIO, M. R. Condomínios residenciais fechados: urbanização do grupo Encalso Damha em São Carlos-SP. 2015.160f. Dissertação. (Mestrado em Ciências Sociais) -Universidade Júlio de Mesquita Filho, Faculdade de Ciências e Letras, Araraquara, 2015.

BRASIL. Lei Federal no 10.257, de 10 de julho de 2001. Estatuto da Cidade. 2001. Disponível em < http://www.planalto.gov.br/ccivil_03/leis/LEIS_2001/L10257.htm> Acesso em: 01 fev. 2016. 


\section{Revista Nacional de}

Gerenciamento de Cidades

National Journal of Cities Management

CORRÊA R. L. O Espaço Urbano. 4.ed. São Paulo: Ática, 2003.94p.

LEFEBVRE, H. The production of space. Oxford: Blackwell,1991.454 p.

PDDUASSC. Plano Diretor de Drenagem Urbana Ambientalmente Sustentável do Município de São Carlos,(Relatório 1), PROCESSO N.o 6.965/07, São Carlos, SP, SHS Engenharia e Projetos de Engenharia. Out. 2009.

PDSC - Lei no 13.691 de 25 de novembro de 2005. Plano Diretor de São Carlos In 1CD-ROM.

PDSC- Lei no 18.05319 DE DEZEMBRO DE 2016. Plano Diretor de São Carlos. Disponível em <http://www.saocarlos.sp.gov.br>Acessado em Dez.2016.

LOPES João Marcos de Almeida; SHIMBO Lúcia Zanin. Projeto e produção da habitação na região central do estado de São Paulo: condições e contradições do PMCMV. Capítulo 9 pág 229-253. Minha Casa... E a Cidade? Avaliação do Programa Minha Casa Minha Vida em seis estados Brasileiros. Caio Santo Amore, Lúcia Zanin Shimbo e Maria Beatriz Cruz Rufino (Organizadores). 1. ed. - Rio de Janeiro : Letra Capital, 2015. 